\title{
O ESTÁGIO CURRICULAR SUPERVISIONADO ENTRE FRONTEIRAS: A ORGANIZAÇÃO DO TRABALHO PEDAGÓGICO E OS DILEMAS DA INTERLOCUÇÃO COM A ESCOLA "REAL"
}

\author{
Álcio Crisóstomo Magalhães \\ Universidade Estadual de Goiás (UEG), Goiânia, Goiás, Brasil \\ JúlIO CÉSAR APOLINÁRIO MAIA \\ Universidade Federal de Jataí (UFJ), Jataí, Goiás, Brasil \\ Lana Kayne Pereira Silva \\ Universidade Federal de Goiás (UFG), Goiânia, Goiás, Brasil
}

\begin{abstract}
RESUMO: Este estudo coloca em questão o processo de instituição de um efetivo diálogo interdisciplinar entre os cursos de formação de professores e as instituições de educação básica parceiras nos projetos de Estágios Curriculares Supervisionados. Por meio da análise do movimento histórico dos mecanismos legais que instituem a obrigatoriedade da organização de Estágios Curriculares Supervisionados em escolas da comunidade, intenta-se mostrar os desafios para a construção dessa interlocução. Estrutura-se a partir dos três momentos constituintes da Pesquisaação: tematização: momento de exposição do referencial teórico; investigação: momento especulativo ou de experimentação do plano de trabalho e síntese dialógica da ação: momento demonstrativo do resultado da investigação.
\end{abstract}

Palavras-chave: Estágio Curricular Supervisionado; Formação de professores; Organização do trabalho pedagógico.

INTRODUÇÃO

Tendo em vista contribuir com os esforços de construção de uma concepção de Estágio Curricular Supervisionado capaz de articular as instituições de formação de professores, os sistemas de ensino e as unidades de educação básica (escolas reais), esse estudo se caracteriza pelo esforço de analisar, a partir de uma Pesquisa-ação, as interfaces que se estabelecem entre o componente curricular Estágio Curricular Supervisionado II (fundamental II e Ensino Médio) de uma Licenciatura em Educação Física e o Projeto 
Político Pedagógico (PPP) de uma escola-campo orientada pelos princípios de uma reforma educacional de matriz neoliberal.

Dito isso, o objetivo é estabelecer os determinantes da justaposição de um projeto de intervenção centrado na categoria trabalho e uma reforma educacional centrada na perspectiva de um dito Ensino Médio inovador enredado pela premissa da aferição de índices.

\section{Metodologia}

Esse estudo parte do pressuposto de que, se por um lado os experimentos educativos sistematizados sob a forma de projeto de intervenção de Estágio Curricular Supervisionado não devem ser tomados como modelos ou fórmulas mágicas para reprodução em larga escala, por outro, devem ser interpretados como eficazes instrumentos de apreensão dos principais determinantes que incidem na relação que se estabelece entre cursos de formação de professores e as unidades de ensino básico parceiras.

Assim sendo, parte-se da compreensão de que o trabalho de um coletivo de estagiários de uma licenciatura em Educação Física em um colégio de Ensino Médio em Tempo Integral da Secretaria da Educação, Cultura e Esporte de Goiás (SEDUCE-GO) organizado pelo "Programa Novo Futuro" permite uma fértil análise de como a concepção de escolas de resultados ou de índices em Goiás vem impactando os projetos de Estágio Curricular Supervisionado. Trata-se de uma Pesquisa-ação ou participante de delineamento não experimental estruturado em três momentos; tematização bibliográfico documento, investigação e ação (BALDISSERA, 2001).

\section{O ESTÁGIO CURRICULAR SUPERVISIONADO E O DILEMA DA RELAÇÃO FORMAÇÃO TEORIA/PRÁTICA}

A relação entre teoria e prática se consolida, especificamente no tocante à formação de professores, e se consagra como um problema de grandeza nacional, haja vista que desde os primeiros anos do período republicano tal relação se ocupa de um caráter interrogativo. Pois:

Com a reforma do ensino público municipal do Rio de Janeiro, em 1897, a partir de onde derivavam, então, diretrizes para o ensino no País, a formação pedagógica passou a ser uma preocupação e a duração do estágio foi definida - seis meses em uma escola primária (ANDRADE e RESENDE, 2010, p. 233).

Contudo, somente na década de 1960 é que esta relação passa a ser discutida nos marcos legais do país, a partir da ideia de Prática de Ensino e Estágio Supervisionado. Em 1962 o Parecer n` 292 do Conselho Federal de Educação (CFE) determinava que a Prática de Ensino, ministrada sob forma de Estágio Supervisionado, se tornasse componente curricular mínimo obrigatório a todos os cursos de formação de professores. Em 1969 a Resolução CFE no 09/69 se tornou uma espécie de divisor de águas com relação ao assunto. $\mathrm{O}$ art. $2^{\circ}$ do documento tornou "obrigatória a Prática de Ensino das matérias que 
[...] [fossem] objeto de habilitação profissional, sob a forma de Estágio Supervisionado a desenvolver-se em situação real, de preferência em escolas da comunidade" (BRASIL, 1969, n.p.).

Ainda que a escola fosse entendida como o lugar de treinamento, a realidade das instituições de ensino regulares passaria a fazer parte da formação dos futuros professores, que até então só tinham contato (quando tinham) com os colégios de aplicação. Até então a Prática de Ensino organizada sob a forma de Estágio Supervisionado não era obrigatória. A Lei no 6.494/77, que regulamenta os indicativos dispostos em ambos os documentos comentados anteriormente, passa a ratificar o novo entendimento legal:

$\S 2^{\circ}$ Os estágios devem propiciar a complementação do ensino e da aprendizagem a serem planejados, executados, acompanhados e avaliados em conformidade com os currículos, programas e calendários escolares, a fim de se constituírem em instrumentos de integração, em termos de treinamento prático, de aperfeiçoamento técnico-cultural, científico e de relacionamento humano (BRASIL, 1977, n.p.).

Essa forma de conceber o real como momento de aplicação de um sistema de ideias, tornou-se ao longo dos anos de ditadura militar uma espécie de princípio da relação teoria/prática. Nesse processo o Estágio Supervisionado ganhou o status de lugar do fazer.

Uma racionalidade técnica constituiu-se, àquele momento especulativo da relação existente entre $\bigcirc$ par teoria/prática, enquanto pensamento força. Tal racionalidade submeteu a formação de professores, sobretudo no que se refere ao Estágio Curricular Supervisionado, ao domínio de modelos de ensino preconcebidos em manuais didáticos. É importante lembrar que nesse contexto o fazer da escola estava orientado pelos princípios da Didática Instrumental. Freitas $(1995$, p. 20) evidencia, com ênfase à década de 1970, "um período em que se havia exaltado o método e a técnica de ensino". O método único de ensinar a todos se tornou, portanto, a referência para a organização dos Estágios Curriculares, que se restringiam à entrega de algumas turmas de uma unidade de ensino de educação básica qualquer a acadêmicos dos últimos semestres das licenciaturas, para que estes pudessem experimentar teorias e treinar sua capacidade de controlar/disciplinar uma turma. Um procedimento, ausente de qualquer diálogo efetivo interinstitucional, restrito a uma relação estabelecida entre os docentes do Estágio e a turma, escolhida para ser literalmente objeto de intervenção, a vista de que inexistia um planejamento organizado em comunhão entre ambas as instituições de ensino, com objetivos, tarefas e avaliações formalmente projetadas. O Estágio se restringia a um professor da instituição formadora, que em geral completava sua carga horária docente com a supervisão de estagiários.

São esses os elementos que vão organizar a relação entre o conhecimento acadêmico e as práticas pedagógicas em Estágio Supervisionado até o final do Século XX. Somente com o ciclo de redemocratização e as consequentes pressões por uma escolarização em sintonia com as demandas dos trabalhadores e dos sujeitos, historicamente marginalizados pelo método único de ensinar, é que a relação teoria/prática passa a ser ressignificada, especialmente no que diz respeito à legislação. $O$ 
fato de a Constituição de 1988 instituir a educação como um dever do Estado, coloca em cena uma concepção de escolarização que torna imprescindível a elaboração de um novo sistema legal, capaz de dar conta de todos os novos imperativos expressos na nova Carta Magna do País. Dado isso:

\begin{abstract}
Pode-se citar como exemplos a luta por uma escola de qualidade; por creches e, depois, pela educação infantil; por eleição direta para diretores das escolas públicas, naquele momento como ato indispensável à construção de um projeto democrático de escola, à criação dos conselhos e à gestão participativa, bandeiras de luta que foram reconhecidas na Constituição Federal de 1988 (CRUZ, 2009, p. 58).
\end{abstract}

A Constituição Federativa do Brasil de 1988 materializa esse conjunto de demandas sociais. É ela que vai, a via de exemplo, criar as condições para a elaboração do Estatuto da Criança e do Adolescente em 1990, para a criação dos órgãos de defesa dos direitos sociais e de proteção da infância e da juventude - a partir do Ministério Público (1988) e Conselho Tutelar (1990) respectivamente. Promulgava-se neste período a consolidação do novo estado social e um ciclo muito importante para a educação pública do Brasil.

A Lei de Diretrizes e Bases da Educação Nacional (LDB) no 9394/96 é um típico produto desse processo histórico que, entre muitas outras novidades, passa a instituir novas mediações na relação entre o quotidiano das escolas e o componente curricular Estágio Supervisionado. $\mathrm{O}$ art. $82^{\circ}$ da LDB, ao tempo que impõe a necessidade de articulação entre os entes federativos na organização de políticas de Estágio, também confere autonomia aos sistemas de ensino que passam a estabelecer "[...] as normas de realização de estágio em sua jurisdição, observada a lei federal sobre a matéria" (BRASIL, 1996, n.p.).

A partir da LDB, em tempos de pós-redemocratização, a relação entre teoria e prática no que se refere ao Estágio Supervisionado é redimensionada, conforme pode se perceber nos pareceres subsequentes, que surgem em função dos dispositivos expressos pela nova Lei da Educação Nacional.

Tendo como objetivo, junto com a prática de ensino, a relação teoria e prática social tal como expressa o Art. $1^{\circ}, \S 2^{\circ}$ da LDB, bem como o Art. $3^{\circ}, \mathrm{XI}$ e tal como expressa sob o conceito de prática no Parecer CNE/CP 09/01, o estágio é o momento de efetivar, sob a supervisão de um profissional experiente, um processo de ensino/aprendizagem que, tornar-se-á concreto e autônomo quando da profissionalização deste estagiário (BRASIL, 2001a, p. 11).

O Estágio torna-se o lugar não somente da execução, mas também de diálogo, observação, interlocução interinstitucional. A prática deixa de ser entendida como cópia da teoria, do mesmo modo que a teoria deixa de ser concebida como reflexo da prática, pois “A prática é o próprio modo como as coisas vão sendo feitas cujo conteúdo é 
atravessado por uma teoria. Assim a realidade é um movimento constituído pela prática e pela teoria como momentos de um dever mais amplo [...]" (BRASIL, 2001b, p. 8).

A partir de tal concepção, fundamentadora da ideia de Prática de Ensino, o Estágio Supervisionado ganha o sentido de experiência de regência formativa integrada ao Projeto Político Curricular do curso, por meio do qual o futuro professor acompanha todos os aspectos da vida escolar que somente podem ser visualizados no quotidiano de uma unidade de ensino. Para tanto,

\begin{abstract}
[...] é preciso que exista um projeto de estágio planejado e avaliado conjuntamente pela escola de formação e as escolas campos de estágio, com objetivos e tarefas claras e que as duas instituições assumam responsabilidades e se auxiliem mutuamente, o que pressupõe relações formais entre instituições de ensino e unidades dos sistemas de ensino. Esses "tempos na escola" devem ser diferentes segundo os objetivos de cada momento da formação. Sendo assim, o estágio não pode ficar sob a responsabilidade de um único professor da escola de formação, mas envolve necessariamente uma atuação coletiva dos formadores (BRASIL, 2001c, p. 58).
\end{abstract}

Esse entendimento supera, por incorporação, a concepção de Estágio Supervisionado como técnica de ensino ou mera disciplina altamente sistematizada sob a forma de conteúdo. O saber fazer torna-se parte de um todo, bem distante de ser tudo. "Ao elaborar seu projeto curricular, a equipe de formadores deve buscar formas de organização, em contraposição às formas tradicionais concentradas exclusivamente em cursos de disciplinas" (BRASIL, 2001c, p. 52). A regência torna-se muito mais que elaboração e aplicação de plano de aula.

Na verdade, se o PPP da unidade de ensino não conceber a aula como unidade central da organização de seu trabalho pedagógico, não fará nenhum sentido a ideia de regência do Estágio Supervisionado centrado na categoria aula. Isso significa dizer que a escola, enquanto componente de uma totalidade que se realiza na combinação de sua localização geográfica, de sua estrutura física e das condições socioeconômicas e políticoculturais do país, corpo discente, docente e quadro administrativo, terá peso fundamental na organização do trabalho pedagógico do Estágio Supervisionado. A escola passa de uma estrutura imutável à disposição do experimento de sistemas de ideias à condição de lócus de diálogo, construção compartilhada e troca, que inclui o Estágio Supervisionado no todo de sua organização de trabalho pedagógico, que passa necessariamente pela elaboração do projeto pedagógico, pelas rotinas de matrícula, organização das turmas e de todos os tempos e espaço escolar.

\footnotetext{
A formação de professores não se faz isoladamente, de modo individualizado. Exige ações compartilhadas de produção coletiva, pois isso amplia a possibilidade de criação de diferentes respostas às situações reais. A construção do projeto pedagógico da escola, por exemplo, é, necessariamente, um trabalho coletivo do qual o professor em formação terá que participar (BRASIL, 2001c, p. 53).
} 
Por esse motivo a escola e as instituições formadoras de professores tornam-se corresponsáveis pela formação de novos professores, conforme se pode aprender também da Resolução do Conselho Pleno (CP) do Conselho Nacional de Educação (CNE) $n^{\circ} 01 / 2002 . \bigcirc$ art. $13^{\circ} \S 3^{\circ}$ deste documento não só recoloca a obrigatoriedade do Estágio Curricular Supervisionado, a partir da segunda metade do curso, ser realizado em escola de educação básica, como também determina que deve ser avaliado conjuntamente pela escola formadora e escola-campo de Estágio.

Os cursos de licenciatura e graduação plena devem, pois, interagir sistematicamente com a educação básica na construção de projetos incomuns de formação dos futuros professores. De acordo com o $\S 6^{\circ}$ da Resolução CNE/CP nº 02/2015, essa articulação entre instituição de educação superior e o sistema de educação básica deve ocorrer em regime de colaboração e envolver a consolidação de fóruns estaduais e distrital permanentes de apoio à formação docente, contemplando a "[...] inserção dos estudantes de licenciatura nas instituições de educação básica da rede pública de ensino, espaço privilegiado da práxis docente" (BRASIL, 2015, p. 5).

Está claro que entre nas licenciaturas e as escolas de educação básica se estabelece um procedimento investigativo. O desenvolvimento profissional, a constituição da identidade docente, bem como a seleção e organização dos conteúdos, a definição de metodologia, envolve necessariamente o levantamento de hipóteses, delimitação de problemas, o registro e a sistematização de informações, a reflexão crítica, a produção e publicização de sínteses que orientem todas as escolhas fundamentais à organização do trabalho pedagógico.

Nesse sentido, o Estágio Supervisionado também se torna ação de arguição da realidade aparente e desenvolvimento de análises que suscitam novas perguntas e integrem a escola com todos os seus agentes, especialmente seu corpo discente na busca de novas respostas, e, por assim dizer, produção de conhecimento. O estagiário "[...] produz conhecimento pedagógico quando investiga, reflete, seleciona, planeja, organiza, integra, avalia, articula experiências, recria e cria formas de intervenção didática junto aos seus alunos para que estes avancem em suas aprendizagens" (BRASIL, 2001c, p. 36).

Portanto fala-se em uma ampliação do que, até então, se concebia como conhecimentos exigidos e competências necessárias aos estagiários. Além da formação específica, conforme exigências das diversas etapas da educação básica, o Estágio Supervisionado deve promover o debate das questões contemporâneas no que diz respeito aos aspectos culturais, sociais e econômicos da vida em sociedade. Conforme determina a Resolução CNE/CP no 01/2002, a Formação de Professores da Educação Básica, em nível superior, deve contemplar:

I - cultura geral e profissional; II - conhecimentos sobre crianças, adolescentes, jovens e adultos, aí incluídas as especificidades dos alunos com necessidades educacionais especiais e as das comunidades indígenas; III- conhecimento sobre dimensão cultural, social, política e econômica da educação; IV - conteúdos das áreas de conhecimento que serão objeto de ensino; $\mathrm{V}$ - conhecimento pedagógico; $\mathrm{VI}$ conhecimento advindo da experiência (BRASIL, 2002, p. 3). 
Nesse novo contexto legal que acaba gradualmente alterando as políticas de Estágio Curricular Supervisionado, a articulação teoria/prática passa a ser tensionada por novas categorias de análise e de ação. Isso implica, por exemplo, na transformação do que historicamente se concebeu como aprendizagem. Isto é, o velho messianismo da noção de conhecimento como algo a ser distribuído por meio de uma generosa transmissão/doação passa a ser confrontado pela ideia de construção contínua, solidária, sem a qual o homem não se faria humanidade. A práxis emerge como novo princípio metodológico geral. Ação-reflexão-ação em unidade e em resposta ao desafio de superar a ditadura do método único de ensinar. Portanto, a subversão do aprender. Da descrição estéril de um evento de natureza qualquer à compreensão de suas razões explicativas.

O Estágio Curricular Supervisionado obrigatório, em articulação intrínseca com as práticas de ensino, conforme determinação literal do Parecer CNE/CP no 09/2001, tornase o eixo de articulação interdisciplinar e de mediação da interlocução crítica entre o conhecimento acadêmico e os saberes específicos do mundo do trabalho docente.

A Resolução CNE/CP no 02/2015 atualiza esse compromisso ao indicar, por meio do art. $5^{\circ}$, que a formação docente deve pautar-se pela educação como processo emancipatório e permanente, que se faz pelo reconhecimento da especificidade do trabalho docente, da compreensão da práxis como a expressão da articulação entre teoria e prática e pela "exigência de que se leve em conta a realidade dos ambientes das instituições educativas da educação básica e da profissão" (BRASIL, 2015, p. 6).

Ao final das duas primeiras décadas do Século XXI, cerca de meio século após a Resolução CFE no 09/1969, que instituiu, via Estágio, a relação entre a universidade e as instituições regulares de ensino básico, o compromisso de articulação entre instituições formadoras de professores e escola "real" é certamente uma das ideias mais recorrentes em todos os marcos legais de regulamentação da formação de profissionais do magistério no Brasil. Essa ideia pode ser entendida como uma das principais marcas de um circuito histórico que se fecha em 2019.

Não por acaso essa é uma proposição que aos poucos se tornou uma espécie de lugar comum por boa parte dos projetos de Estágios Supervisionados das instituições de formação de professores em todo o Brasil.

Contudo, o grande desafio ao longo desses anos, muito especialmente nas últimas três décadas, foi promover a transposição do conjunto legal para a realidade quotidiana, o local das disputas pela interpretação e seleção do frio da letra e do embate concreto das correlações de forças que ininterruptamente colocam em xeque as diferentes ideologias que se chocam, mas que em geral se acomodam no inerte corpo da lei.

Essa tem sido, talvez, a grande demanda para os cursos de formação de professores ao longo desse ciclo de 50 anos. Como fazer com que a relação entre as instituições formadoras, os sistemas de ensino e as unidades de educação básica vá além de um mero acordo formal de Estágio Curricular Supervisionado? A Escola Superior de Educação Física e Fisioterapia de Goiás (ESEFFEGO), unidade da Universidade Estadual de Goiás, desde os anos 1990 vem se interrogando.

\section{O ESTÁGIO CURRICULAR SUPERVISIONADO EM ESCOLAS "REAIS" E OS LIMITES DA FORMAÇÃO TÉCNICA: O CASO DA EDUCAÇÃO FÍSICA}


O processo de retomada da expansão econômica-autoritária, com ênfase no desenvolvimento industrial, centrado na produção de bens de capital e privilégio dos grupos empresariais, no que diz respeito à questão educacional, escolheu como estratégia de reorganização do ensino público brasileiro, após o golpe civil-militar de 1964, a entrega do sistema educacional, por meio de convênios como os Acordos MECUSAID, aos técnicos da Agência para o Desenvolvimento Internacional do Governo dos Estados Unidos. A Lei no 5.540/68, uma das expressões do reformismo advindo dessas parcerias, cria uma série de gatilhos para a transformação da estrutura e funcionamento do ensino. Além, por exemplo, da Resolução CFE no 09/69 - que torna obrigatória a Prática de Ensino em escolas da comunidade (situação real) sob a forma de Estágio Supervisionado.

Além disso, essa nova lei mobilizou o CFE a instituir, por meio da Resolução no $69 / 69$, que a formação de professores de Educação Física passaria a ser feita em curso de graduação de duração entre três e cinco anos e conferiria o título de Licenciado em Educação Física e Técnico em Desportos, sendo três anos para a licenciatura e até mais dois anos para os acadêmicos que pretendessem acumular o título de técnicos em modalidades esportivas.

A combinação desses dois dispositivos conduziu os cursos de formação de professores de Educação Física a adotar uma concepção de Estágio Curricular Supervisionado em total comunhão com o princípio da prática entendida como cópia da teoria e da teoria como reflexo da prática. A ideia que pairava sobre a formação de um professor "técnico em" induziu a transformação das quadras das escolas de $1^{\circ}$ e $2^{\circ}$ graus em lócus do Estágio Supervisionado. Instituir essa concepção de professor de Educação Física no mesmo contexto socioeconômico e político-cultural em que houve transformação das unidades de ensino da comunidade (escola real) em local da Prática de Ensino sob a forma de Estágio Curricular supervisionado, fecundou um modelo didático que limitou o debate interinstitucional entre os cursos de licenciaturas em Educação Física e as escolas. Ainda que de forma não explícita ou intencional, alijou-se, por um lado, escolas pelo país do direito à experiência do Estágio, e por outros acadêmicos com relação ao conhecimento acerca da totalidade das questões educacionais.

A ideia de Estágio como Prática de Ensino eminentemente técnica, no caso da Educação Física, criava um novo pressuposto. Ainda que isso não estivesse escrito em lugar algum (até porque não poderia), a teoria da área, isto é, a Prática de Ensino sob a forma de Estágio, só poderia ser praticada nas escolas que possuíssem quadras poliesportivas ou campos. Como o Brasil chegou aos anos 1960 apresentando grande carência de infraestrutura escolar em todos os níveis, apenas uma pequena parcela das unidades de ensino, especialmente as centrais, poderia estabelecer relação com os cursos de formação de professores.

Assim, as raras quadras, das poucas escolas que as possuíam, se tornaram os campos de regência para os futuros professores de educação física que, por sua vez acabavam tendo suas experiências formativas em uma amostra quase insignificante da realidade educacional do país, seja pela limitação da ação apenas no interior dos espaços específicos às práticas esportivas ou pela falta de oportunidades de expansão do olhar para o todo que compunham as paisagens escolares. 
Somente após a abertura democrática, com a ação enérgica dos movimentos sociais em defesa de uma educação pública, gratuita e para todos, o que impactou sobremaneira as bases epistemológicas da Educação Física e ensejou a criação do sistema legal de formação de professores e de regulação das políticas de Estágio Curricular Supervisionado, esse quadro foi alterado.

Em complementação à Resolução CFE no 09/69, que determinava a realização do Estágio em ambientes escolares reais e regulares e em articulação estreita com os sistemas de ensino e com as escolas, o Parecer CFE n 215/87 e a Resolução CFE nº 03/1987 apareceram como resposta ao problema da Educação Física limitada ao espaço quadra e à premissa técnica. $O$ primeiro considerando que a "formação profissional harmonizar-seia a necessária unidade dos princípios filosóficos educacionais da Educação Física nacional, com os interesses, necessidades e peculiaridades regionais" (BRASIL, 1987a, p. 4) e o segundo definindo que "os currículos plenos para os cursos de graduação em Educação Física [teriam] [...] duas partes: a) Formação Geral (humanística e técnica); b) Aprofundamento de Conhecimentos" (BRASIL, 1987b, n.p.) - que a formação geral deveria considerar o conhecimento filosófico, o conhecimento do ser humano, o conhecimento da sociedade e que o conhecimento técnico deveria ser articulado com as áreas de cunho humanístico -, deram um novo sentido ao todo da formação de professores de Educação Física, inclusive na ampliação das possibilidades de Estágios Curriculares, ao promover o fim da licenciatura curta, ampliar a concepção de currículo, efetivando exigências mais estreitas sobre o currículo mínimo e aumentando para 2.880 o número mínimo obrigatório de horas para a integralização dos cursos.

Esse reordenamento vem provocando alterações profundas na organização curricular das graduações em Educação Física por todo o país, como se pode perceber no movimento histórico da Licenciatura em Educação Física da ESEFFEGO. O curso foi criado em 1962 muito em sintonia com os princípios que viriam orientar o processo socioeconômico e político-cultural implementado no país à força a partir de 1964, e desde o início da década de 1990 vem empenhando um grande sacrifício para se transformar em lócus de formação de professores de Educação Física a partir de uma perspectiva geral humanística e técnica com aprofundamento de conhecimentos.

É nesse contexto histórico e social que o corpo docente e discente do curso de graduação em Educação Física da ESEFFEGO se insere com a missão nada fácil de fazer emergir, de forma democrática e competente, uma revisão curricular que dialogue com a necessidade de qualificar seu projeto pedagógico e curricular (GOIÁS, 2015, p. 3).

Nesse enfrentamento coletivo, o Estágio Curricular Supervisionado tem sido um dos principais desafios. Após uma década de maturação dos elementos teóricometodológicos necessários à construção de uma experiência de prática curricular sob forma de Estágio em consonância com as mais recentes deliberações legais e, principalmente, com as demandas dos movimentos sociais, a ESEFFEGO impôs-se o desafio de transformar sua concepção de relação teoria e prática no que se refere ao elemento Estágio Curricular Supervisionado.

Disso, cria, em 2010, o Núcleo de Estudo e Pesquisa em Estágio (NEPE), que desde então passa a construir, por meio do diálogo acadêmico, um projeto de Estágio Curricular Supervisionado Obrigatório ancorado em uma concepção de formação ampliada em 
Educação Física que considere a crítica, reflexiva e investigativa, como princípio da organização do trabalho pedagógico; a cultura corporal como objeto de mediação com a realidade; a articulação estreita com os sistemas de ensino e com as escolas da comunidade goiana como condição para a parceria NEPE/unidade de ensino; e o Estágio como componente privilegiado da retroalimentação da matriz curricular do curso.

Para além de um mero exercício de iniciação à prática da regência de turmas de educação formal, o NEPE/ESEFFEGO vem buscando dar sentido formativo à relação universidade/escola, isto é, passar da mera relação burocrática interinstitucional à uma situação de parceria político-pedagógica, por meio da qual entram em diálogo agentes de realidades distintas (professores, diretores, coordenadores, pais, estudantes, acadêmicos, etc.), mas em estreita conexão, seja em função da indissociabilidade que se estabelece entre universidade, sistemas de ensino e escola, ou pelas múltiplas determinações socioeconômicas e político culturais.

Nesse esforço de construção o NEPE vem partindo da experiência concreta no interior das escolas de educação básica, parceiras na formação de professores de Educação Física para subsidiar o debate acerca dos limites e possibilidades do diálogo no atual contexto de reforma educacional centrada na ideologia da meritocracia.

\section{A EDUCAÇÃO FÍSICA ESCOLAR E A PEDAGOGIA DA PRÁXIS: AS LUTAS COMO MEDIAÇÃO}

No âmbito da Educação Física escolar, os acadêmicos da ESEFFEGO juntamente com seus orientadores de Estágio Supervisionado, desenvolvem experiências reais em contextos escolares difusos e diversos de ensino. Diante a parceria provocada entre a universidade e o campo de Estágio/a escola, percebeu-se a necessidade de pesquisar e analisar a organização do trabalho pedagógico que envolta toda essa construção formativa. Nesse sentido, buscou apoiar-se na pedagogia da práxis sob a concepção crítica de sociedade assentada numa instituição de educação básica que tem em sua racionalidade a meritocracia como alicerce do seu cotidiano.

Todas as formas de expressão corporal organizadas sob a forma de jogos, danças, lutas, exercícios ginásticos, esportes, malabarismos, contorcionismos, mímicas, dentre outros são chaves de leitura da realidade. $O$ esforço do homem para fazer-se humanidade, se expressa nos elementos da cultura corporal. Conforme entendimento do Coletivo de Autores (1992) o sujeito movimentando-se guarda indícios de um modo coletivo de sentir, pensar e agir no mundo. Nesse sentido, os tradicionais conteúdos da Educação Física são mediações explicativas do real, mapas de leitura das sociedades em suas problemáticas socioeconômicas e político-culturais diversas.

A partir desta concepção é possível apropriar-se das lutas como chave de leitura de um mundo que se organiza em torno do dilema entre a essência e aparência. Ao considerar essa justaposição do conteúdo, ela se torna o ponto de partida para uma série de intervenções que se mostraram relevantes nas ações pedagógicas mediadas pela concepção práxica de educação em campo de Estágio Supervisionado.

As lutas permeiam a humanidade desde seus primórdios, o homem que veio se adaptando e se desenvolvendo ao longo dos contextos históricos e socioeconômicos nos deixam uma "herança cultural" que deflagra conflitos e contradições presentes na 
sociedade (e na modernidade). De acordo com Dias Junior (2014) A divisão social do trabalho e a fragmentação da sociedade em classes, carregam em si um novo sentido para o "combate", passam a se orientar pelos princípios de saúde e competição, de modo que

[...] não encontra mais sentido na elevação da técnica ou questões de vida e morte, mas sim na necessidade histórica de forjar o campeão de cada modalidade. Estas produções são determinadas - não sem tensão -, em maior ou menor medida, pelo capitalismo. Os que aceitam o desafio de socializar pedagogicamente as lutas se deparam com esta contradição (DIAS JUNIOR, 2014, p. 80).

Mobilizado por essa problemática é que o coletivo de acadêmicos da ESEFFEGO lançou-se ao desafio de envolver três turmas de primeira série do Ensino Médio de uma unidade de ensino de Goiânia no debate acerca do fenômeno social "lutas" por meio do Estágio Supervisionado.

A fim de dar trato pedagógico à discussão e atender a racionalidade organizacional do Colégio, a temática foi fracionada em subunidades ou blocos.

Em uma primeira subunidade foi apresentada a seguinte problematização: Considerando as Artes Marciais Mistas (MMA), ou o que a grande mídia apresenta como combate hoje, questiona-se, qual a essência disso que se convencionou chamar de lutas? O questionamento se findou acerca da relação essência/aparência, mediada pela reflexão das características, aspectos históricos e conflitos na atualidade pela modalidade Kung $\mathrm{Fu}^{\prime}$.

A partir dessa proposição abre-se uma nova questão: considerando a relação essência/aparência expressa na relação Wushu/Kung $F u$, como se pode explicar o processo de alteração da essência de um traço de cultura? Essa inquietação suscita a interlocução com a modernização conservadora das colônias brasileiras. Os determinantes desse processo sobre a Capoeira ${ }^{2}$ - desde sua condição de Ritual N'golo em solo africano, até as disputas entre as vertentes "Regional" e "Angola" no Brasil mediaram toda a abordagem de essência da luta, enquanto raiz e enquanto ressignificação/transformação a partir do processo de colonização. Para Abib (2006) há uma relação dialógica entre os valores dessa prática e a realidade próxima das escolas dos países colonizados. Este sentido de comunhão entre elementos das práticas corporais marginais e a cultura dos povos colonizados permite aos estudantes, especialmente das frações de classe trabalhadora, entender sua existência e fazer reverberar seu princípio e sua origem. Permite ainda que se sensibilizem para a complexidade das condições sóciopolíticos e econômicas que os cercam (RADICCHI, 2013).

Essa discussão acerca da busca de uma raiz, do fundamento da realidade aparente ou próxima, permitiu às turmas de primeiros anos do Ensino Médio submetidas ao Estágio Supervisionado pensarem e refletirem sobre o sentido da cultura corporal na modernidade. Assim, foi possível colocar em xeque a essência da mais midiática forma de combate do início do Século XXI - o MMA - através da organização de um torneio de lutas orientado pela premissa do olimpismo esportivo para o consumo, isto é, pela racionalidade de um evento de combate organizado a partir dos princípios da luta transformada em mercadoria. 


\section{À GUISA DE CONCLUSÃO: ESCOLA DE RESULTADOS, ESTÁGIO SUPERVISIONADO E O DESAFIO DA INTERLOCUÇÃO}

Os acordos e compromissos expressos nos documentos oficiais e transpostos recentemente nos PPP das escolas e redes de ensino expressam o sentido que vem se atribuindo à escola no contexto de intensificação de globalização e flexibilização capitalista. Preocupados com uma elevação apenas quantitativa dos resultados, o poder público vem construindo um único argumento para validar o fazer da escola. Este argumento, como evidenciado por Belo e Amaral (2013), pode orientar as escolas públicas a uma focalização em avaliações e metas que acabam não conferindo visibilidade aos verdadeiros problemas que acometem a escola pública brasileira.

Tal concepção de escolarização por resultados oferece grandes desafios para o diálogo interdisciplinar entre a universidade, os sistemas de ensino e o coletivo das unidades de educação básica. Na verdade, o processo tem esbarrado sobremaneira na racionalidade da aferição total de índices. Como o único indicador de qualidade das unidades de ensino tem sido o escore quantitativo (o índice objetivo), a ação docente nos sistemas submetidos a esse princípio de quantificação, classificação e reclassificação contínua, acaba sendo enredada. Então, a menos que as instituições formadoras também se alinhem às políticas de obtenção de índices, acaba se abrindo um grande fosso entre aquilo que a universidade tem concebido como formação e o que os sistemas de ensino têm adotado como políticas de escolarização básica.

A lógica de rearticulação da escola pública a partir da premissa da avaliação total para obtenção de índices limita a organização da atividade docente. $O$ trabalho como categoria ontológica, nessa perspectiva instrumental de testes para a classificação, deixa de ser a premissa fundante. Isso porque toda a organização pedagógica das unidades de ensino passa a ser condicionada por aquilo que será cobrada nas provinhas, provões e simulados. A ação dos estagiários de uma licenciatura em Educação Física da cidade de Goiânia em um Colégio Estadual de Período Integral, da SEDUCE-GO, confirma essa tese. Apesar do grande esforço do coletivo da ESEFFEGO em tentar dialogar com a comunidade escolar, a conversa normalmente se apresentou limitada pelo princípio avaliativo que orienta hoje grande parte das escolas estaduais de Goiás, em função do estado neoliberal e meritocrático. O produto passa a ser o grande fim almejado, o que significa a submissão de todos os demais elementos estruturantes da organização do trabalho pedagógico a esse determinante.

Essa racionalidade avaliativa, focada no quantitativo "nota", não se enquadra dentro de um processo práxico de educação. Isso porque, segundo Freitas (1995), quando a centralidade do ato educativo está nas práticas avaliativas sob condições alienantes de organização escolar, o papel da escola gira em torno de: a) fragmentação de conteúdos e consequente isolamento destes e b) incidência no papel de avaliações que objetivam quase que exclusivamente, o controle disciplinar e a indução motivacional, a organização do trabalho pedagógico tende a retornar a uma perspectiva didática instrumental e perder o sentido tanto para professores como para estudantes.

O Estágio Curricular Supervisionado em um ambiente de ensino real em Goiás tem indicado esse retrocesso. A avaliação quantitativa é o que de fato vem ordenando 
todas as rotinas do Sistema de Ensino e em certo sentido limitando o que deveria ser uma concepção ampliada de Estágio.

Artigo recebido em: 29/01/2019

Aprovado para publicação em: 28/05/2019

\begin{abstract}
SUPERVISED CURRICULAR INTERNSHIP BETWEEN BORDERS: THE PEDAGOGICAL WORK'S ORGANIZATION AND THE INTERLOCUTION DILEMMAS WITH THE “REAL" SCHOOL
\end{abstract}

ABSTRACT: This study calls into question the establishing process an effective interdisciplinary dialogue between teacher training courses and partner institutions in Supervised Curricular projects. Through the historical movement analysis of legal mechanisms that impose the Supervised Curricular Internships obligatoriness in community schools, we try to show the challenges for the construction of this interlocution. It's structured from the three constituent moments of the Action Research: thematization - exposition moment of the theoretical reference; research - speculative moment or the work plan experimentation and action dialogical synthesis moment demonstrative of the investigation result.

KEYWORDS: Supervised internship; Teacher training; Pedagogical work organization.

LA PASANTÍA CURRICULAR SUPERVISADA ENTRE FRONTERAS: LA ORGANIZACIÓN DEL TRABAJO PEDAGÓGICO Y LOS DILEMAS DE LA INTERLOCUCIÓN CON LA ESCUELA “REAL”

RESUMEN: Este estudio pone en cuestión el proceso de establecimiento de un efectivo diálogo interdisciplinario entre los cursos de formación de profesores y las instituciones de educación básica asociadas en los proyectos de Pasantías Curriculares Supervisadas. Por medio del análisis del movimiento histórico de los mecanismos legales que instituyen la obligatoriedad de la organización de Pasantías Curriculares Supervisadas en escuelas de la comunidad, se intenta mostrar los desafíos para la construcción de esa interlocución. Se estructura a partir de los tres momentos constituyentes de la Investigación Acción: tematización - momento de exposición del referencial teórico; investigación - momento especulativo o de experimentación del plan de trabajo y síntesis dialógica de la acción - momento demostrativo del resultado de la investigación.

PALABRAS CLAVE: Etapa curricular supervisada; Formación de profesores; Organización del trabajo pedagógico.

\title{
NOTAS
}

1) Segundo Morcazel et al. (2013), o Kung Fu corresponde à arte marcial em si, ou "arte de guerra" e foi ressignificado pela ocidentalização dos esportes de combate. Deriva do termo chinês Wushu, porém, corresponde a uma perda de sentido original em função do olimpismo mercadológico da esportivização. 
2) Por ser considerada uma manifestação cultural altamente fertilizada pelos processos históricos, ao ser pedagogicamente tratada, a capoeira apresenta uma possibilidade de revelação do real ou da realidade próxima dos estudantes, especialmente das escolas de países colonizados. Isso porque, permite a esses sujeitos o entendimento de seu próprio passado e a crítica da visão convencionalmente apresentada pelos veículos de comunicação de massa. Abib (2006) considera que uma prática pedagógica orientada pelas manifestações da cultura popular tem o potencial de desenvolver a sensibilidade, a criatividade, o lúdico e a expressão, ou seja, tem um poder humanizante do ser.

\section{REFERÊNCIAS}

ABIB, Pedro Rodolpho. Cultura popular, educação e lazer: uma abordagem sobre a capoeira e o samba. Práxis Educativa, v.1, n.1, p.58-66, jan/jun, 2006.

ANDRADE, Rosana Cássia Rodrigues. RESENDE, Marilene Ribeiro. Aspectos legais do estágio na formação de professores: uma retrospectiva histórica. Educação em Perspectiva, v.1, n.2, p.230-252, jul./dez. 2010.

BALDISSERA, Adelina. Pesquisa-ação: uma metodologia do "conhecer" e do "agir" coletivo. Sociedade em Debate, v. 7, n. 2, p. 5-25, ago, 2001.

BELO, Fernanda Ferreira; AMARAL, Nelson Cardoso. IDEB da escola: a aferição da qualidade do ensino tem sido referencial para se (re)pensar a educação municipal? Revista Educação e Políticas em Debate, v.2, n.2, p.339-353, jul./dez. 2013.

BRASIL. Resolução CFE no 09, de 10 de outubro de 1969. 1969. Disponível em: <http://cev.org.br/biblioteca/resolucao-n-9-10-outubro-1969>. Acesso em: 20 jan. 2019.

. Lei n 6.494 , de 07 de dezembro de 1977. Dispõe sobre os estágios de estudantes de estabelecimentos de ensino superior e de ensino profissionalizante do $2^{\circ}$ Grau e Supletivo e dá outras providências. Diário Oficial da União, Brasília, DF, 9 dez. 1977.

. Parecer CFE n 215, de 11 de março de 1987. Reestruturação dos cursos de graduação em Educação Física, sua nova caracterização, mínimos de duração e conteúdo. Documenta, Brasília, DF, n.315, mar. 1987a.

. Resolução CFE nº3, de 16 de junho de 1987. Fixa os mínimos de conteúdo e duração a serem observados nos cursos de graduação em Educação Física (Bacharelado e/ou Licenciatura Plena). Diário Oficial da União, Brasília, DF, n.172, 22 jun. 1987b.

. Lei n. ${ }^{\circ}$ 9.394, de 20 de dezembro de 1996. Estabelece as diretrizes e bases da educação nacional. Diário Oficial da União, Brasília, DF, 23 dez. 1996. 
. Parecer CNE/CP n 21, de 08 de maio de 2001. Dispõe sobre a duração e carga horária dos cursos de Formação de Professores da Educação Básica, em nível superior, curso de licenciatura, de graduação plena. Conselho Nacional de Educação, Brasília, 06 ago. 2001a.

Parecer CNE/CP n²8, 08 de maio de 2001. Dá nova redação ao Parecer CNE/CP 9/2001, que dispõe sobre as Diretrizes Curriculares Nacionais para a Formação de Professores da Educação Básica, em Cursos de Nível Superior. Conselho Nacional de Educação, Brasília, DF, 02 out. 2001 b.

Parecer CNE/CP n 09, de 08 de maio de 2001. Diretrizes Curriculares Nacionais para a Formação de Professores da Educação Básica, em nível Superior, curso de licenciatura, de graduação Plena. Conselho Nacional de Educação, Brasília, DF, 08 mai. 2001c.

Resolução CNE/CP nº 01, de 18 de fevereiro de 2002. Estabelece Diretrizes Nacionais para a Educação em Direitos Humanos. Conselho Nacional de Educação, Brasília, DF, 18 fev. 2002.

Resolução CNE/CP no 02, de 01 de julho de 2015. 2015. Define as Diretrizes Curriculares Nacionais para a formação inicial em nível superior (cursos de licenciatura, cursos de formação pedagógica para graduados e cursos de segunda licenciatura) e para a formação continuada. Conselho Nacional de Educação, Brasília, DF, 01 jul. 2015.

COLETIVO DE AUTORES. Metodologia do ensino de educação física. São Paulo: Cortez, 1992.

CRUZ, José Adelson da. O movimento social e a escola: da criação passada à invenção necessária. EccoS Revista Científica, v.11, n.1, p.57-75, jan./jun. 2009.

DIAS JUNIOR, Elson. Metodologia do ensino das lutas: uma proposição críticosuperadora. In: CONGRESSO NORDESTE DE CIÊNCIAS DO ESPORTE, 5., 2014, Guanambi. Trabalhos do grupo temático 5 - Escola. Guanambi: UNEB, 2014.

FREITAS, Luiz Carlos de. Crítica da organização do trabalho pedagógico e da didática. Campinas: Papirus, 1995.

GOIÁS. Universidade Estadual de Goiás. Escola Superior de Educação Física e Fisioterapia do Estado de Goiás. Projeto pedagógico do curso de licenciatura em educação física. 2015.

KOPPE, Vinício Renner. O kung fu tradicional e o wushu moderno. Trabalho de conclusão de graduação (Licenciatura em Educação Física). Porto Alegre: Universidade Federal do Rio Grande do Sul, UFRGS, 2009. 
MORCAZEL, Rafael Carvalho da Silva; MURAD, Mauricio; CAPINUSSÚ, José Maurício. O kung-fu wushu e os jogos olímpicos: história e possibilidades de inserção. Revista Corpus et Scientia, v.9, n.1, p.115-125, jan, 2013.

RADICCHI, Marcelo Rocha. Capoeira e escola: significados da participação. Várzea Paulista: Fontoura, 2013.

Álcio Crisóstomo MagalHÃes: Doutor em Educação pela Faculdade de Educação da Universidade de Goiás.

Áreas de investigação: Educação, trabalho e movimentos sociais com foco em organização do trabalho pedagógico em Educação Física e cultura política.

Orcid: https://orcid.org/0000-0003-0940-9665

E-mail: alciocri@smail.com

Júlo CésAR Apolinário Mala: Mestrando em Educação pela Universidade Federal de Jataí (PPGE/UFJ). Linha de pesquisa: Formação Humana e Fundamentos da Educação. Temas de interesse: Organização do trabalho pedagógico em Educação Física Escolar; Currículo e Educação Física; Diretrizes Pedagógicas da Educação Física Brasileira; Mundo do trabalho e Eucação Física.

Orcid: https://orcid. org/0000-0002-7162-2136

E-mail: jcesarm@outlook.com

Lana Kayne Pereira Silva: Mestranda em Ensino na Educação Básica pela Universidade Federal de Goiás/CEPAE. Linhas de pesquisa e interesse temático: Educação Física escolar e formação de professores.

Orcid: https://orcid.org/0000-0001-5152-4558

E-mail:lanakayne@hotmail.com

Este periódico utiliza a licença Creative Commons Attribution 3.0, para periódicos de acesso aberto (Open Archives Iniciative - OAI). 